\title{
REM sleep behaviour disorder differentiates pure autonomic failure from multiple system atrophy with autonomic failure
}

Giuseppe Plazzi, Pietro Cortelli, Pasquale Montagna, Alessandro De Monte, Raffaella Corsini, Manuela Contin, Federica Provini, Giulia Pierangeli, Elio Lugaresi

\begin{abstract}
Ten patients with primary autonomic failure, followed up in a prospective clinical and laboratory study, were finally diagnosed as pure autonomic failure or multiple system atrophy with autonomic failure. Polysomnographic studies were performed in all patients. Whereas all four patients with multiple system atrophy complained of sleep related episodes suggesting REM sleep behaviour disorder (RBD) confirmed by polysomnography, RBD remained absent in the remaining six patients with pure autonomic failure. The data indicate that RBD is an important clinical feature, often heralding multiple system atrophy, but which is absent throughout the course of pure autonomic failure; its recognition can thus be useful in the prognostic evaluation of early primary autonomic failure syndromes.
\end{abstract}

(F Neurol Neurosurg Psychiatry 1998;64:683-685)

Keywords: REM sleep behaviour disorder in primary autonomic failure; multiple system atrophy; pure autonomic failure

Institute of Clinical Neurology, University of Bologna, Via Ugo Foscolo 7, 40123

Bologna, Italy

G Plazzi

P Cortelli

P Montagna

A De Monte

R Corsini

M Contin

F Provini

G Pierangeli

E Lugaresi

Correspondence to: Dr Giuseppe Plazzi, Istituto di Clinica Neurologica

Università di Bolognavia Ugo Foscolo, 70123 Bologna,

Italy.

Telephone 003951585158 ; fax 0039516442165 .

Received 22 July 1997 and in revised form 19 September 1997

Accepted 25 September 1997

Primary autonomic failure syndromes comprise pure autonomic failure and multiple system atrophy with autonomic failure. ${ }^{1}$ Pure autonomic failure is confined to the autonomic system, whereas multiple system atrophy with autonomic failure often, though not invariably, presents with autonomic failure but later becomes complicated with signs of CNS involvement such as parkinsonism and cerebellar ataxia. ${ }^{2}$ Pure autonomic failure has a nearly normal life expectancy, whereas multiple system atrophy with autonomic failure has a much more severe prognosis. Differential diagnosis between the two conditions is therefore important, but often difficult especially in the early stages, when autonomic failure in multiple system atrophy may remain isolated in the absence of CNS involvement. In patients with primary autonomic failure, a follow up time of at least five years is required before a definite diagnosis is reached. ${ }^{3}$ Moreover, there are no clearly differentiating laboratory tests as the early differential diagnostic value of supine plasma noradrenaline concentrations, which are often reduced in pure autonomic failure and normal or slightly raised in multiple system atrophy, is still debated. ${ }^{146}$

The vast majority $(90 \%)$ of patients with multiple system atrophy have REM sleep behaviour disorder (RBD), ${ }^{7}$ intense sleep related motor or verbal paroxysmal episodes occurring during REM sleep but without loss of muscle tone. ${ }^{8}$ The episodes usually appear at least one hour after falling asleep, coinciding with REM sleep, occur intermittently during the night, are often more intense during the early morning hours, and are accompanied by the recall of vivid, fearful dreams. RBD represents the most common clinical sleep manifestation and polysomnographic finding in multiple system atrophy, ${ }^{7}$ and often heralds the appearance of the other CNS symptoms by years. $^{79} \mathrm{RBD}$ is attributed to involvement of the neural structures in the brain stem controlling muscle atonia during REM sleep. ${ }^{8}{ }^{10}$ As the brain stem remains largely spared in pure autonomic failure whereas it is severely involved in multiple system atrophy, ${ }^{11}$ we ascertained whether RBD could distinguish patients with primary autonomic failure .
Ten de novo patients (seven men, three women, mean age 59.6 (range 40-67) years) with primary autonomic failure were enrolled the disorder. Possible orthostatic hypotension symptoms were blurred vision, dizziness, weakness, neckache, nausea, falls, or syncope appearing on assuming the erect posture. Other autonomic signs included, impotence, micturitional urgency, sphincter dysfunction and loss of sweating.

Patients underwent neurological examination, brain CT or MRI, tilting test, plasma noradrenaline concentrations supine and after 10 minutes of head up tilt test, ${ }^{12}$ and videopolysomnography. They were followed up for a mean period of 4.8 (range 2-7) years and the examinations were repeated every year, until a conclusive diagnosis was reached. No patient was lost on follow up. Orthostatic hypotension was defined on tilting tests as a reduction of systolic blood pressure of at least $20 \mathrm{~mm} \mathrm{Hg}$ or

\section{Material and methods} in a prospective study to assess the evolution of 
diastolic blood pressure of at least $10 \mathrm{~mm} \mathrm{Hg}$ not before the third minute and during 10 minutes of head up position at an angle of $65^{\circ} . .^{1}$ Possible secondary causes of orthostatic hypotension were ruled out by appropriate tests. ${ }^{13}$

Videopolysomnographic recordings were performed with extended montages including EEG (C3-A2, C4-A1, O1-A2, O2-A1), right and left EOG, surface EMG from chin, intercostal, right and left tibialis anterior and right and left extensor digitorum communis muscles, microphone, nasal air flow, thoracic respirogram, ECG, and oxygen saturation. Paper speed was $10 \mathrm{~mm} / \mathrm{s}$ and sleep stages were scored according to the criteria suggested by Rechtschaffen and Kales ${ }^{14}$ with allowance for intermittent or sustained loss of REM atonia defining RBD. ${ }^{15}$

\section{Results}

At the first observation all patients had autonomic failure unassociated with signs of CNS involvement. A tilt test confirmed orthostatic hypotension (table) in all patients (mean decrease in systolic blood pressure 60.2 (SD 26.5) $\mathrm{mm} \mathrm{Hg}$; mean decrease in diastolic blood pressure 21.6 ( SD 14.9) $\mathrm{mmHg}$ ). Brain CT or MRI was normal in all the patients.

A minimum five year follow up (range 5-7 years) established that six patients had pure autonomic failure (four men, two women; mean age 58.8 (range 40-67) years). The other four patients developed unequivocal signs of CNS involvement within one to three years of follow up and were thus considered cases of multiple system atrophy with autonomic failure (table).

At first observation five of six patients with pure autonomic failure had extremely low supine noradrenaline concentrations, ranging from 16 to $187 \mathrm{pg} / \mathrm{ml}$ (normal values from 29 age matched healthy controls: 242 (SD) 100 $\mathrm{pg} / \mathrm{ml}$; range $108-500 \mathrm{pg} / \mathrm{ml}$ ). A blunted noradrenaline head up tilt test response was found in five of six patients (table). No differences were detectable in systolic or diastolic blood pressure decreases on tilt testing between the two groups of patients. No patient with pure autonomic failure complained of sleep related motor or verbal manifestations associated with fearful dreams, suggestive of RBD, throughout the follow up period. On polysomnography, all six patients with pure autonomic failure had a normal REM sleep pattern, with physiological REM atonia. Their sleep structure was characterised by a sleep efficiency ranging from 57 to $78 \%$ (mean 66\%). Sleep stage percentages were stages $1-269.3 \%$ (range $54.8 \%-83 \%$ ), slow wave sleep $8.4 \%$ (range $1.5 \%-20.2 \%$ ), and REM sleep $15.6 \%$ (range $8.2 \%-25.3 \%$ ). One patient had snoring with normal $\mathrm{HbSaO}_{2}$ concentrations. Repeated polysomnography throughout the follow up ruled out a late appearance of RBD.

Four patients (three men, one woman; mean age 60; range 55-66 years) developed cerebellar or extrapyramidal signs within 1.7 (SD 0.9) years of follow up. In particular two patients presented with cerebellar and extrapyramidal signs, one with cerebellar signs and the other with parkinsonism with associated pyramidal signs. None of them responded to levodopa. Plasma supine noradrenaline concentrations were normal in two patients (226 and 229 $\mathrm{pg} / \mathrm{ml}$ ) and below the normal range in the other two $(72 \mathrm{pg} / \mathrm{ml}$ in both), with a normal increase on head up tilting in two of four patients (table). All of them complained of possible RBD episodes since the ages of 40 to 60 (mean 51.5 years), with a frequency from two to three episodes a week to more than one episode every night. In three patients RBD episodes began one, four, and 20 years after onset of autonomic failure while in the fourth case they were concomitant with autonomic failure. In this group sleep efficiency ranged from $32 \%$ to $75 \%$. Sleep structure was characterised by $74.7 \%$ of light sleep (range $66.6 \%-91.7 \%$ ), $6.8 \%$ of slow wave sleep (range $1.7 \%-10.4 \%$ ), and $15.6 \%$ of REM sleep (range $6.6 \%-23.4 \%$ ). Videopolysomnographic recordings showed RBD in all of these patients since the first observation. Motor activity during the RBD ranged from a pronounced increase in myoclonic activity, with massive trunk and limb jerks, to complex oneiric behaviour with gesticulations, talking, yelling, fighting, or fleeing behaviour. One patient had eight apneas an hour with minimal $\mathrm{HbSaO}_{2}$ at $88 \%$. Two

Clinical and autonomic features of patients with autonomic failure

\begin{tabular}{|c|c|c|c|c|c|c|c|c|c|c|c|c|c|}
\hline $\begin{array}{l}\text { Patient } \\
\text { no }\end{array}$ & Sex & $\begin{array}{l}\text { Final } \\
\text { diagnosis }\end{array}$ & $\begin{array}{l}\text { Present } \\
\text { age }(y)\end{array}$ & $\begin{array}{l}\text { Follow } \\
\text { up }(y)\end{array}$ & $\begin{array}{l}A F \\
\text { onset } \\
(y)\end{array}$ & $\begin{array}{l}R B D \\
\text { onset } \\
(y)\end{array}$ & $\begin{array}{l}C \text { sign } \\
\text { onset } \\
(y)\end{array}$ & $\begin{array}{l}\text { E sign } \\
\text { onset } \\
(y)\end{array}$ & $\begin{array}{l}S P D \\
(m m ~ H g)\end{array}$ & $\begin{array}{l}D P D \\
(m m \mathrm{Hg})\end{array}$ & $\begin{array}{l}\text { Rest NA } \\
(p g / m l)\end{array}$ & $\begin{array}{l}\text { Tilt NA } \\
\text { (pg/ml) }\end{array}$ & $\begin{array}{l}\triangle \mathrm{NA} \\
(\mathrm{pg} / \mathrm{ml})\end{array}$ \\
\hline 1 & $M$ & PAF & 67 & 5 & 52 & - & - & - & -61 & -24 & 38 & 60 & +22 \\
\hline 2 & M & PAF & 67 & 5 & 62 & - & - & - & -85 & -31 & 38 & 65 & +27 \\
\hline 3 & $M$ & PAF & 46 & 6 & 37 & - & - & - & -40 & -20 & 37 & 144 & +107 \\
\hline 4 & $\mathrm{~F}$ & PAF & 71 & 6 & 63 & - & - & - & -76 & -23 & 187 & 122 & -65 \\
\hline 5 & $\mathrm{~F}$ & PAF & 74 & 7 & 56 & - & - & - & -54 & -15 & 24 & 24 & 0 \\
\hline 6 & $M$ & PAF & 55 & 5 & 46 & - & - & - & -80 & -35 & 16 & 27 & +11 \\
\hline 7 & $\mathrm{~F}$ & MSA & 58 & 3 & 52 & 52 & 58 & - & -27 & 0 & 72 & 126 & +54 \\
\hline 8 & $M$ & MSA & 71 & 6 & 60 & 40 & 68 & 68 & -106 & -51 & 72 & 86 & +14 \\
\hline 9 & $M$ & MSA & 61 & 3 & 55 & 54 & 56 & 56 & -24 & -6 & 229 & 402 & +173 \\
\hline 10 & $M$ & MSA & 67 & 2 & 64 & 60 & - & 65 & -49 & -11 & 226 & 406 & +180 \\
\hline
\end{tabular}

$\mathrm{AF}$ onset=age at onset of autonomic failure; RBD onset=age at onset of RBD; follow up=duration of observation from first presentation at our Institute until final diagnosis; $\mathrm{C}$ sign onset=age at onset of cerebellar signs; $\mathrm{E}$ sign onset=age at onset of extrapyramidal signs; $\mathrm{SPD}=$ systolic blood pressure decrease $(\mathrm{mm} \mathrm{Hg})$ on tilt test at the first observation; $\mathrm{DPD}=$ diastolic blood pressure decrease $(\mathrm{mm} \mathrm{Hg})$ on tilt test at the first observation; rest NA=noradrenaline concentrations at rest (supine) at the first observation (normal values from 29 age matched healthy controls: 242 (SD 100) pg/ml; range 108-500 pg/ml); tilt NA=norepinephrine concentrations after 10 minutes head up tilt at the first observation (normal values from 29 age matched healthy controls: 441 (SD 147) pg/ml; range $246-836 \mathrm{pg} / \mathrm{ml}) ; \Delta \mathrm{NA}=$ difference in noradrenaline concentrations between 10 minutes head up tilt and baseline values at the first observation (normal values from 29 age matched healthy controls: 199 (SD $77 \mathrm{pg} / \mathrm{ml}$ ) range 111-366 pg/ml). 
patients had snoring, two laryngeal stridor, and one periodic limb movements during sleep accompanied by EEG arousals.

\section{Discussion}

Our study indicates that, within the primary autonomic failure syndromes, RBD is confined to multiple system atrophy, and probably represents a tell tale sign of extensive pathological involvement of the brain stem, which is absent in pure autonomic failure. Neuropathological degeneration in pure autonomic failure remains confined within the peripheral autonomic system, especially the postganglionic sympathetic neurons, with limited brainstem involvement. ${ }^{11}$ On the contrary, the pathology of multiple system atrophy is characterised by widespread involvement of the peripheral, autonomic, and central nervous systems. ${ }^{111617}$ Damage to the REM sleep atonia cells of the pons probably represents the pathological change causing RBD in multiple system atrophy. ${ }^{7}$ In three of four patients with multiple system atrophy RBD heralded onset of autonomic failure, confirming previous data in the literature. ${ }^{79} \mathrm{~A}$ delayed emergence of the parkinsonian signs or other signs of multiple system atrophy in patients with RBD has already been described. ${ }^{79}{ }^{18}$ However, in patient $8 \mathrm{RBD}$ preceded the appearance of autonomic failure by 20 years, a long time delay compared with the other cases (one and four years). In our previous multiple system atrophy material, RBD preceded the other signs of multiple system atrophy by one to 19 years, whereas in the literature the longest delay reported is three years. ${ }^{9}$ The rather long gap between RBD and onset of autonomic failure in patient 8 remains puzzling, but it is noteworthy that this patient also displayed a rather slow progression of the other signs of multiple system atrophy. Future studies with more patients with RBD may clarify this issue, which implies that in some cases multiple system atrophy may have a quite prolonged disease course.

RBD split our autonomic failure population in two, without overlap, and therefore seems to have a good diagnostic specificity. Even though ours is a small series, RBD had more diagnostic specificity than the supine noradrenaline concentrations, which showed partial overlap between the two groups of patients. Furthermore, the finding of a plasma noradrenaline response to head up tilting similar to that in normal subjects in three out of 10 patients is in keeping with previous data, ${ }^{19}$ suggesting that measurement of the change in plasma noradrenaline with postural stimulation may be misleading in autonomic failure. In fact, increases in plasma concentrations of the neurotransmitter can occur after a reduction in its plasma clearance.
Alongside RBD, breathing disorders during sleep such as laryngeal stridor were found in multiple system atrophy in patients with autonomic failure, but not in all of them or in the early stages. Changes in sleep structure were non-specific and did not differentiate the two groups.

In conclusion, RBD is an important clinical sign in autonomic failure, and when present RBD most probably heralds multiple system atrophy. Clinical and polysomnographic investigation for this peculiar sleep related disturbance may improve the differential diagnosis in patients presenting with isolated autonomic failure.

1 The Consensus Committee of the American Autonomic Society and the American Academy of Neurology. Consensus statement on the definition of orthostatic hypotension, pure autonomic failure and multiple system atrophy. Neurology 1996;46:1470.

2 Wenning GK, Ben Shlomo Y, Magalhães M, et al. Clinical features and natural history of multiple system atrophy. An analysis of 100 cases. Brain 1994;117:835-45.

3 Bannister R, Mathias CJ. Clinical features and investigation of the primary autonomic failure syndromes. In: Bannister R, Mathias CJ, eds. Autonomic failure. A textbook of clinical disorders of the nervous system. 3rd ed. London: Oxford Unidisorders of the nervous system.
versity Press, 1992:531-547.

4 Ziegler MG, Lake CR, Kopin IJ. The sympathetic nervous system defect in primary orthostatic hypotension. $N$ Engl $\mathcal{F}$ Med 1977;296:293-7.

5 Polinsky RJ, Kopin IJ, Ebert MH, et al. Pharmacologic distinction of different orthostatic hypotension syndromes. Neurology 1981;31:1-7.

6 Polinsky RJ. Neuropharmacological investigation of autonomic failure. In: Bannister R, Mathias CJ, eds. Autonomic failure. A textbook of clinical disorders of the nervous system. 3rd ed. London: Oxford University Press, 1992:334-58.

7 Plazzi G, Corsini R, Provini F, et al. REM sleep behavior disorders in multiple system atrophy. Neurology 1997;48: 1094-7.

8 Schenck CH, Bundlie SR, Ettinger MG, et al. Chronic behavioral disorders of human REM sleep: a new category of parasomnia. Sleep 1986;9:293-308.

9 Tison F, Wenning GK, NP Quinn, et al. REM sleep behavTison F, Wenning GK, NP Quinn, et al. REM sleep behav-
iour disorder as the presenting symptom of multiple system atrophy [letter]. F Neurol Neurosurg Psychiatry 1995;58: atrophy

10 Jouvet $M$, Delorme F. Locus coeruleus et sommeil paradoxal. C R Soc Biol 1965;159:895-9.

11 Daniel SE. The neuropathology and neurochemistry of multiple system atrophy. In: Bannister R, Mathias CJ, eds. Autonomic failure. A textbook of clinical disorders of the nervous system. 3rd ed. London: Oxford University Press, 1992: 564-585.

12 Cortelli P, Pierangeli G, Parchi P, et al. Autonomic nervous system function in migraine without aura. Headache 1991; 31:457-62

13 Mathias CJ, Bannister R. Investigation of autonomic disorders. In: Bannister R, Mathias CJ, eds. Autonomic failure. A textbook of clinical disorders of the nervous system. 3rd ed. textbook of clinical disorders of the nervous system.

14 Rechtschaffen A, Kales A. A manual of standardized terminology, techniques and scoring system for sleep stages of human subogy, techniques and scoring system for sleep stages of human sub-
jects. Los Angeles: Brain Information Service, Brain jects. Los Angeles: Brain

15 Schenck CH, Mahowald MW. Polysomnographic, neurologic and psychiatric and clinical outcome report on 70 consecutive cases with REM sleep behavior disorder (RBD): sustained clonazepam efficacy in $89.5 \%$ of 57 treated patients. Cleve Clin f Med 1990;57:10-24.

16 Lockwood AH. Shy-Drager syndrome with abnormal respirations and antidiuretic hormone release. Arch Neurol 1976;33:292-5.

17 Oppenheimer D. Diseases of the basal ganglia, cerebellum and motor neurons. In: Adams JH, Corsellis JAN, Duchen LW, eds. Greenfield's neuropathology. 4th ed. New York: Wiley, 1984:699-747.

18 Schenck CH, Bundlie SR, Mahowald MW. Delayed emergence of a parkinsonian disorder in $38 \%$ of 29 older men initially diagnosed with idiopathic rapid of 29 older men initially diagnosed with idiopathic rapid eye move-

ment sleep behavior disorder. Neurology 1996;46:388-93.

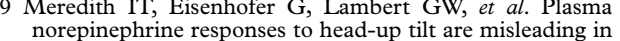
norepinephrine responses to head-up tilt are mis.
autonomic failure. Hypertension 1992;19:628-33. 